\title{
Ribosome binding site libraries and pathway modules for shikimic acid synthesis with Corynebacterium glutamicum
}

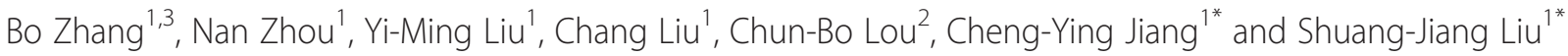

\begin{abstract}
Background: The shikimic acid (SA) pathway is a fundamental route to synthesize aromatic building blocks for cell growth and metabolic processes, as well as for fermentative production of various aromatic compounds. Genes encoding enzymes of SA pathway are not continuous on genome and they are differently regulated.

Results: In this study, efforts were made to construct continuous genetic modules of SA pathway that are regulated by a same Ptac promoter. Firstly, aro genes [aroG (NCgl2098), aroB (NCgl1559), aroD (NCgl0408) and aroE (NCg|1567)] from Corynebacterium glutamicum and ribosome binding site (RBS) libraries that were tailored for the above genes were obtained, and the strength of each RBS in the 4 libraries was quantified. Secondly, 9 genetic modules were built up from the RBS libraries, a previously characterized ribozyme insulator (RiboJ) and transcriptional promoter (Ptac) and terminator, and $\operatorname{aroG}, \operatorname{aroB}, \operatorname{aroD}$ and $\operatorname{aro} E$. The functionality and efficiency of the constructed genetic modules were evaluated in C. glutamicum by determination of SA synthesis. Results showed that C. glutamicum RES167 $\triangle$ aroK carrying a genetic module produced $4.3 \mathrm{~g} / \mathrm{L}$ of SA, which was 54 folds higher compared to that of strain RES167 $\triangle$ aroK ( $80 \mathrm{mg} / \mathrm{L}$, without the genetic module) during fermentation in 250-mL flasks. The same strain produced 7.4, and $11.3 \mathrm{~g} / \mathrm{L}$ of SA during 5-L batch and fed-batch fermentations, respectively, which corresponding to SA molar yields of 0.39 and 0.24 per mole sucrose consumption.
\end{abstract}

Conclusion: These results demonstrated that the constructed SA pathway modules are effective in increasing SA synthesis in C. glutamicum, and they might be useful for fermentative production of aromatic compounds derived from SA pathway.

Keywords: Shikimic acid pathway, Corynebacterium glutamicum, Shikimate production, Synthetic biology, Genetic modules, Ribosome binding site (RBS)

\section{Background}

The shikimic acid (SA) pathway exists in prokaryotes and plants, and is the common route for the synthesis of aromatic amino acids (Trp, Phe, Tyr) [1-3] and vitamins such as phylloquinone [4]. Since its discovery, the SA pathway has attracted extensive interest from science and industries. Recent investigations have demonstrated that more chemicals can be produced by expanding the SA pathway [5]. Seven steps of reactions complete the SA pathway, leading to the conversion of phosphoenolpyruvate (PEP) and erythrose 4-phophate (E4P) to chorismic

\footnotetext{
* Correspondence: jiangcy@im.ac.cn; liusj@im.ac.cn

${ }^{1}$ State Key Laboratory of Microbial Resources, Institute of Microbiology, Chinese Academy of Sciences, Beichen-Xilu No.1, 100101 Beijing, PR China Full list of author information is available at the end of the article
}

acid [1]. In Corynebacterium glutamicum, the aro genes encoding DAHP synthase (aroG/ncgl2098), 3-dehydroquinate synthase (aroB/ncgl1559), 3-dehydroquinate dehydratase (aroD/ncgl0408) and shikimate dehydrogenase (aroE/ ncgl1567) are involved in conversion of PEP and E4P to shikimic acid, and they are located at different transcriptional regulation units [6-9] (Fig. 1). Recent study showed that transcription of $\operatorname{aro} E$ was correspondent to the levels of shikimate in C. glutamicum [9]. Genes encoding the enzymes of SA pathway are not continuous on genome and are differently regulated; this would results in extra difficulties for genetic manipulation and metabolic engineering of SA pathway. 


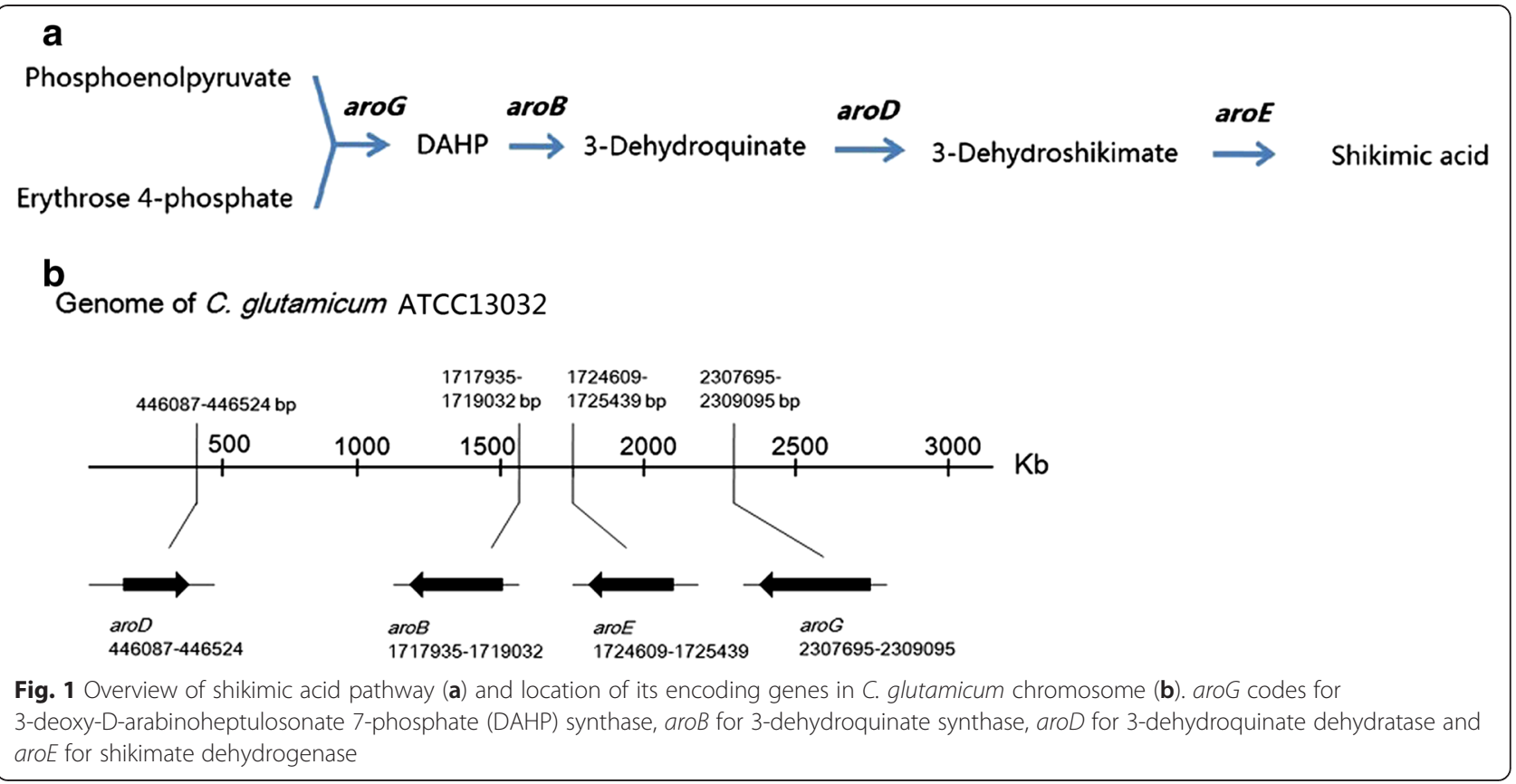

The development of synthetic biology brings new concepts to design and construct genetic modules or metabolic engineering for bioprocesses. Genetic elements that regulate transcription, translation or encode various enzymes are used as "parts" to build genetic modules [10, 11]. Ideally, the properties of the parts and modules can be accurately and quantitatively predicted when they are implanted into chassis cells [12, 13]. Recently, scientists have designed and constructed a series of parts libraries of promoters, ribosome binding sites (RBS) and terminators, which enabled the regulation of gene expression over wide dynamic ranges in Escherichia coli cells [14, 15]. For example, RBS of different strengths have been applied to optimize the metabolic flux of mevalonate-based farnesyl pyrophosphate biosynthetic pathway [16]. So far, synthetic parts and modules are very limited for C. glutamicum, an important industry production workhorse that has been used for decades to produce amino acids, vitamins, nucleotides [17-20], and recently biofuels and chemicals [21-24].

In this study, efforts were made to construct continuous genetic modules for SA pathway with synthetic biology logistics. Four RBS libraries that were tailored for C. glutamicum and 9 genetic modules for SA synthesis were constructed. The functionality and efficiency of the constructed SA pathway modules were evaluated by determination of SA production with C. glutamicum. Results suggested that the newly constructed pathway modules were effective. During batch and fed-batch fermentation, SA production reached titers of 7.4 and $11.3 \mathrm{~g} / \mathrm{L}$, respectively. This represented the highest titer of fermentative production of SA with C. glutamicum.

\section{Results}

Design, construction, and screening of RBS libraries for aroB, aroD, aroE and aroG

RBS sequences such as AGAAAGGAGG and GAAAGG AGG [25-27] had been previously identified in C. glutamicum. In addition, the sequence of AAAGGAGGA had been used for expression of genes involving in biopolyester synthesis with C. glutamicum [28]. All these RBS sequences shared a common feature of AAAGGAGG, which is correspondent to the anti-Shine-Dalgarno sequence at the 3'-end of the 16S rRNA from corneybacteria [26]. In addition, it was reported that the spaces between RBS and translational start codon were found to be dominantly 5-10 nucleotides in C. glutamicum [27]. Based on these observations, we generalized a seeding sequence of AAAGG(N) $)_{6-9}$. According to this design, a pool of RBS sequences was chemically synthesized.

For easy screening of RBS sequences of different strengths and for the purpose to prevent the influence of neighboring elements on gene translation, the enhanced green fluorescence protein (eGFP) [29] and the ribozymebased insulator RiboJ [30] genes were applied to make constructions for screening tailored RBS libraries for individual aroG, aroB, aroD and aroE. Construction and screening of the tailored RBS libraries are diagramed in Fig. 2. As showed in Fig. 2, 146, 52, 59 and 54 clones were randomly selected for aroB, aroD, aroE and aro $G$, respectively. Plasmids harboring RBS sequences of different strengths were extracted from $E$. coli clones, and were further sequenced. These plasmids were then transferred into C. glutamicum. RBS of different strengths were screened 


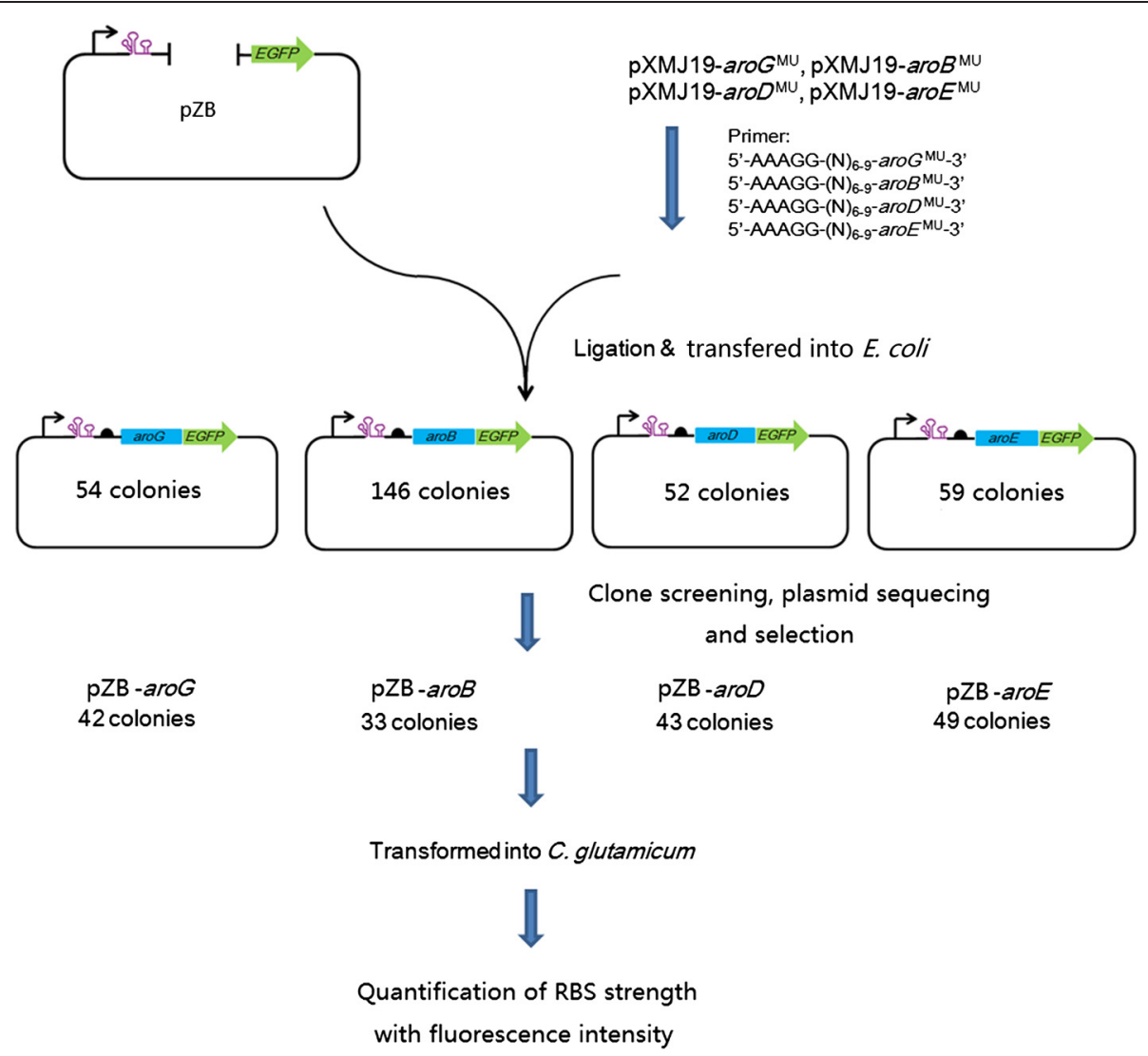

Fig. 2 Procedures of construction and screening of RBS libraries tailored for $\operatorname{aroG}$, aroB, aroD and aroE. Numbers of RBS sequences in each library are represented by the clone numbers of E. coli or C. glutamicum

by quantification of fluorescence intensities in C. glutamicum, and finally 4 RBS libraries were obtained that had 33, 43, 49 and 42 members for aroB, aroD, aroE and aroG, respectively. The RBS sequences of these libraries and the strength of individual RBS are showed in Fig. 3. As seen from Fig. 3, the strengths of the RBS libraries spanned wide ranges. Specifically, the individual RBS strengths of aroB, aroD, aroE and aroG libraries had 70, 21, 19 and 10folds differences, respectively.

\section{Construction and evaluation of genetic modules for SA pathway}

The above RBS libraries were exploited to build up genetic modules for SA pathway. Each genetic module had $\operatorname{aro} B$, aroD, aroE and aro $G$ genes that were independently regulated by RBS of different strengths. The organization of the genetic modules is generalized in Fig. 4a. To simplify the construction and evaluation of genetic modules, RBS with relative high $(\mathrm{H})$, medium (M) or low (L) strength (Fig. 3) from each of the four libraries, were selected for aroG, aroB, aroD or aroE. Starting with these building blocks (3 RBS of different strengths and 4 genes with the order of aroG-aroBaroD-aroE), there were theoretical 81 combinations (i.e. genetic modules that possible have different levels of gene expression). By using a mathematic model of combinatorial approach, such 81 combinations were scaled down to 9 combinations (Fig. 4c).

Genetic modules of the above 9 combinations were constructed and were inserted into pXMJ19. Thus, 9 pXMJ19 derivatives, namely plasmid-1 to plasmid-9, were obtained and were transferred into C. glutamicum RES167 $\triangle$ aroK cells. To determine that if gene translations in the genetic modules were exactly correlated to their RBS strengths as they were previously determined, shikimate dehydrogenase (AroE) activities were determined. As shown in (Fig. 4b), those modules $\left(\mathrm{G}^{\mathrm{H}} \mathrm{B}^{\mathrm{L}} \mathrm{D}^{\mathrm{L}} \mathrm{E}^{\mathrm{L}}, \mathrm{G}^{\mathrm{M}} \mathrm{B}^{\mathrm{H}} \mathrm{D}^{\mathrm{M}} \mathrm{E}^{\mathrm{L}}\right.$, and $\mathrm{G}^{\mathrm{L}} \mathrm{B}^{\mathrm{M}} \mathrm{D}^{\mathrm{H}} \mathrm{E}^{\mathrm{L}}$ ) harbored low strengths of RBS exhibited low AroE activities and those modules $\left(\mathrm{G}^{\mathrm{H}} \mathrm{B}^{\mathrm{H}} \mathrm{D}^{\mathrm{H}} \mathrm{E}^{\mathrm{H}}\right.$, $G^{M} B^{M} D^{L} E^{H}$, and $G^{L} B^{L} D^{M} E^{H}$ ) harbored higher strengths of RBS exhibited higher AroE activities. These results suggested that levels of gene translations in the 9 genetic modules were highly correlated to RBS strengths determined previously via EGFP fluorescence intensities. 


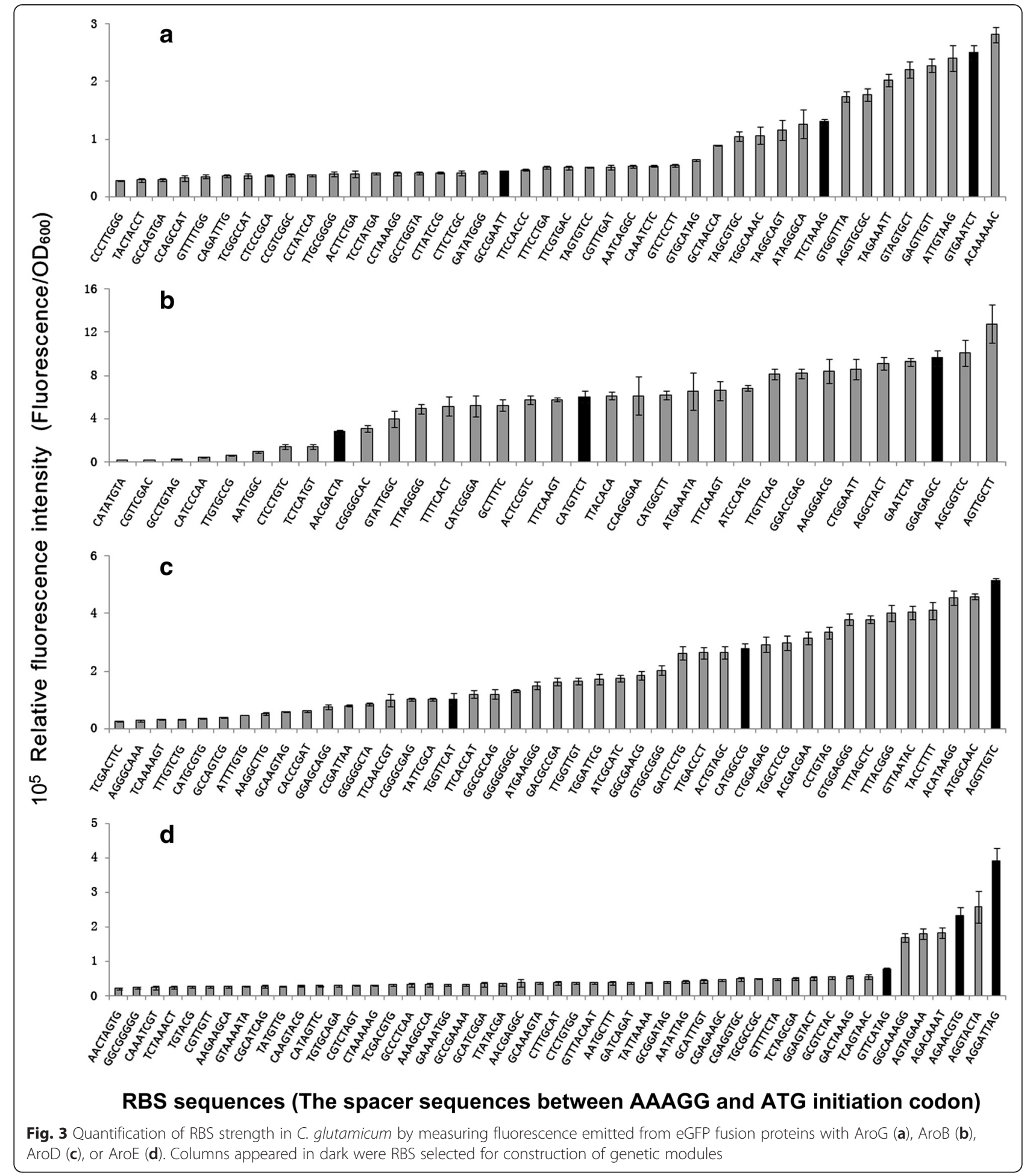

Genetic modules increased SA synthesis with C. glutamicum

In order to obtain a mutant that accumulated SA, the aroK that encodes shikimate kinase was deleted from $C$. glutamicum RES167, generating the mutant RES167 $\triangle$ aroK.
Plasmids (Table 1) harboring the SA pathway modules (Fig. 4c) were transferred into C. glutamicum RES167 1 aroK cells and the effect of those genetic modules on SA production was observed. Results showed that the SA production varied significantly among different genetic modules (Fig. 5), 
a

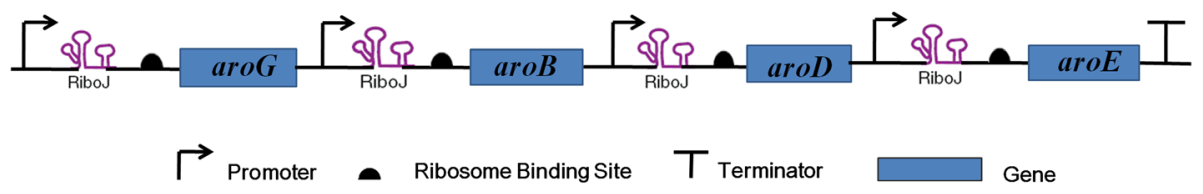

b

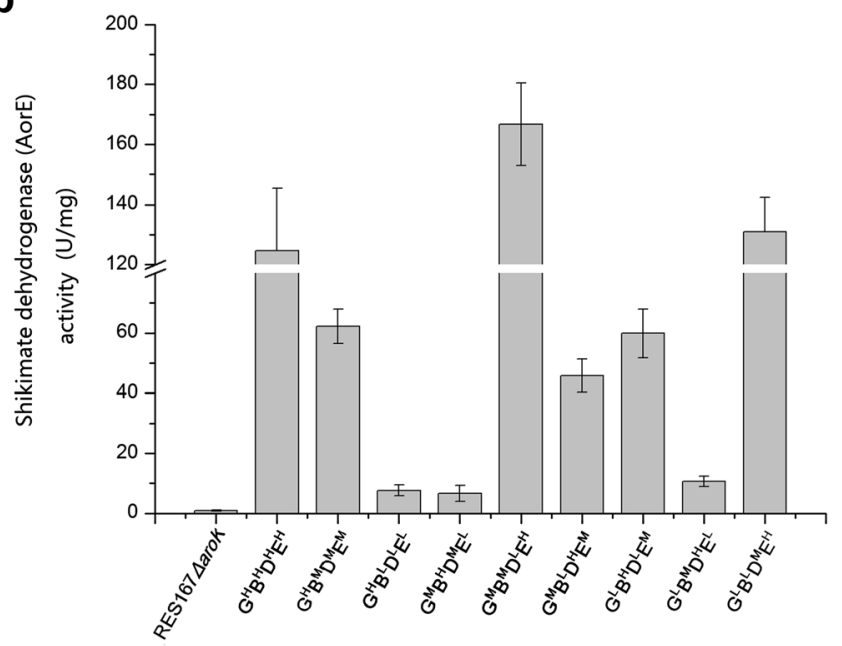

C

\begin{tabular}{lll|l|l|l|l|l|l|l|l|} 
AroG & H & H & H & M & M & M & L & L & L \\
AroB & H & M & L & H & M & L & H & M & L \\
AroD & H & M & L & M & L & H & L & H & M \\
AroE & H & M & L & L & H & M & M & L & H
\end{tabular}

Fig. 4 The components and structure of the genetic modules (a) and AroE activities from cellular lysates of C. glutamicum harboring various genetic modules (b). In panel $\mathbf{b}$, the RBS were determined by a combinatorial approach (c). For each aroG, aroB, aroD and aroE gene, three levels of RBS strength [high $(H)$, medium $(M)$, low $(L)$, see Fig. 3] were selected, and totally 9 genetic modules were obtained. Three parallel experiments for AroE activity were performed and the standard deviations are showed in panel $\mathbf{b}$

although the growth of C. glutamicum was not affected by those genetic modules (Data not shown). The SA production with RES167 $\triangle$ aroK/plasmid-2 that carried genetic module of $\mathrm{G}^{\mathrm{H}} \mathrm{B}^{\mathrm{M}} \mathrm{D}^{\mathrm{M}} \mathrm{E}^{\mathrm{M}}$ was 6.8 higher than that of RES167 $\triangle$ aroK, suggesting that the module of $\mathrm{G}^{\mathrm{H}} \mathrm{B}^{\mathrm{M}} \mathrm{D}^{\mathrm{M}} \mathrm{E}^{\mathrm{M}}$ was the most effective combination for SA synthesis in C. glutamicum.

Insertion of transcriptional terminators into genetic modules further increased SA production with $C$. glutamicum

The genetic module $\mathrm{G}^{\mathrm{H}} \mathrm{B}^{\mathrm{M}} \mathrm{D}^{\mathrm{M}} \mathrm{E}^{\mathrm{M}}$ was designed that there is a tac promoter for each gene but only one terminator after the last gene (Fig. 4a). Since terminator regulates also gene transcription and subsequently translation, 3 new SA pathway modules with insertion of terminators were constructed (Fig. 6a). The SA productions with those new combinations by $C$. glutamicum are shown in Fig. 6b. It was found that insertion of a terminator between aroB and $\operatorname{aroD}\left(\mathrm{G}^{\mathrm{H}} \mathrm{B}^{\mathrm{M}} \mathrm{TD}^{\mathrm{M}} \mathrm{E}^{\mathrm{M}}\right)$ resulted in improvement of SA production by about $56 \%$ (Fig. 6b).

\section{SA production in 250-mL flasks and 5-L fermenters with C. glutamicum RES167 $\triangle$ aroK/pXMJ19-GBTDE}

To evaluate SA productivity, C. glutamicum RES167 4 aroK/ pXMJ19-GBTDE was cultivated in 250-mL flasks and 5-L fermenters. Cell growth, SA production, consumption of sucrose and accumulation of 3-dehydroshikimate were monitored (Fig. 7a, 7b, 7c). SA productions were 4.3, 7.4, and $11.3 \mathrm{~g} / \mathrm{L}$ during $250-\mathrm{mL}$ flask, 5-L batch and fed-batch fermentations, respectively. SA yields from sucrose were 0.22, 0.39, 0.24 mol SA per mole sucrose consumption. 
Table 1 Bacterial strains and plasmids used in this study

\begin{tabular}{|c|c|c|}
\hline Strains/plasmids & Relevant characteristics & Source/reference/notes \\
\hline \multicolumn{3}{|l|}{ Strains } \\
\hline E. coli DH5a & $\begin{array}{l}\mathrm{F}^{-} \text {endA1thi-1 recA1 relA1 gyrA96deo } R \oplus 80 d \text { lac } \Delta(\text { lacZ) M15 } \\
\Delta\left(\text { (lacZYA-argF)U169hsdR17( } \mathrm{r}_{\mathrm{K}}^{-}, \mathrm{m}_{\mathrm{K}}^{+}\right) \lambda^{-} \text {supE44 phoA }\end{array}$ & Invitrogen \\
\hline C. glutamicum RES167 & Restriction-deficient mutant of ATCC 13032, $\Delta$ (cg/lM-cgIIR-cgll/R) & University of Bielefeld \\
\hline Res167ムaroK & Res 167 derivate, a fragment of DNA encoding for aroK was deleted & This study \\
\hline Res167AaroK/pZB-aroG & Res167AaroK derivate, containing plasmid pZB-aroG & This study \\
\hline Res167 $\triangle$ aroK/pZB-aroB & Res $167 \triangle a$ aroK derivate, containing plasmid pZB-aroB & This study \\
\hline Res167\aroK/pZB-aroD & Res167DaroK derivate, containing plasmid pZB-aroD & This study \\
\hline Res167 $\triangle$ aroK/pZB-aroE & Res167 AaroK derivate, containing plasmid pZB-aroE & This study \\
\hline \multicolumn{3}{|l|}{ Plasmids } \\
\hline pK18mobsacB & Mobilizable vector, for gene disruption in C. glutamicum & University of Bielefeld \\
\hline pK18mobsacB-aroK & Derived from pK18mobsacB, carrying aroK gene & This study \\
\hline pK18mobsacB- $\triangle a r o K$ & Derived from pK18mobsacB-aroK, a 573 bp fragment of aroK was deleted & This study \\
\hline pUC19-RiboJ & pUC19 carrying Ribo J & Sangon Biotech \\
\hline PACGFP & Plasmid carrying enhanced green fluorescence protein (GFP) gene & Invitrogen \\
\hline pXMJ19 & Shuttle vector (Cam', Ptac, lacla, pBL1 oriV C.g/u. pK18 oriV E. coli. $)$ & University of Bielefeld \\
\hline pXMJ19-RiboJ & pXMJ19 carrying RiboJ gene & This study \\
\hline pZB & Derived from pXMJ19, carrying both RiboJ and GFP genes & This study \\
\hline pZB-aroG & Derived from $\mathrm{pZB}$, carrying aroG $\mathrm{GU}^{\mathrm{MU}}$ gene with various $\mathrm{RBS}$ & This study \\
\hline pZB-aroD & Derived from $\mathrm{pZB}$, carrying aro $^{\mathrm{MU}}$ gene with various RBS & This study \\
\hline pZB-aroB & Derived from $p Z B$, carrying $\operatorname{aro}^{\mathrm{MU}}$ gene with various RBS & This study \\
\hline pZB-aroE & Derived from $\mathrm{pZB}$, carrying aro $E^{\mathrm{MU}}$ gene with various RBS & This study \\
\hline pXMJ19-aroG $G^{\mathrm{MU}}$ & pXMJ19 carrying aroG of which recognition sites of HindIII and Pstl were mutated & This study \\
\hline pXMJ19-aroB $B^{\mathrm{MU}}$ & pXMJ19 carrying aroB of which recognition sites of BamHI and Spel were mutated & This study \\
\hline pXMJ19-aroD $\mathrm{MU}$ & pXMJ19 carrying aroD of which recognition site of Pstl were mutated & This study \\
\hline pXMJ19-aroE $E^{\mathrm{MU}}$ & pXMJ19 carrying aroE of which the recognition sites of EcoRI and Sall were mutated & This study \\
\hline pXMJ19-RiboJ-aroG $\mathrm{MU}_{-H}$ & pXMJ19 carrying RiboJ and aroG $G^{\mathrm{MU}}$ gene with high strength RBS & This study \\
\hline pXMJ19-RiboJ-aroG ${ }^{\mathrm{MU}}-\mathrm{M}$ & pXMJ19 carrying RiboJ and aroG ${ }^{\mathrm{MU}}$ gene with medium strength RBS & This study \\
\hline pXMJ19-RiboJ-aroG ${ }^{\mathrm{MU}}-\mathrm{L}$ & pXMJ19 carrying RiboJ and aroG $G^{\mathrm{MU}}$ gene with low strength RBS & This study \\
\hline pXMJ19-RiboJ-aroB ${ }^{M U}-H$ & pXMJ19 carrying RiboJ and $\operatorname{aroB}^{\mathrm{MU}}$ gene with high strength RBS & This study \\
\hline pXMJ19-RiboJ-aroB ${ }^{\mathrm{MU}}-\mathrm{M}$ & pXMJ19 carrying RiboJ and $\operatorname{aroB}^{\mathrm{MU}}$ gene with medium strength RBS & This study \\
\hline pXMJ19-RiboJ-aroB ${ }^{\mathrm{MU}}-\mathrm{L}$ & pXMJ19 carrying RiboJ and $\operatorname{aroB}^{\mathrm{MU}}$ gene with low strength RBS & This study \\
\hline pXMJ19-RiboJ-aroD $\mathrm{MU}_{-H}$ & pXMJ19 carrying RiboJ and aroD ${ }^{\mathrm{MU}}$ gene with high strength RBS & This study \\
\hline pXMJ19-RiboJ-aroD ${ }^{M U}-M$ & pXMJ19 carrying RiboJ and aroD ${ }^{\mathrm{MU}}$ gene with medium strength RBS & This study \\
\hline pXMJ19-RiboJ-aroD ${ }^{M U}-L$ & pXMJ19 carrying RiboJ and $\operatorname{aroD}^{\mathrm{MU}}$ gene with low strength RBS & This study \\
\hline pXMJ19-RiboJ-aroE ${ }^{\mathrm{MU}}-\mathrm{H}$ & pXMJ19 carrying RiboJ and aro $E^{\mathrm{MU}}$ gene with high strength RBS & This study \\
\hline pXMJ19-RiboJ-aroE $E_{-M}$ & pXMJ19 carrying RiboJ and aro $E^{\mathrm{MU}}$ gene with medium strength RBS & This study \\
\hline pXMJ19-RiboJ-aroE ${ }^{\mathrm{MU}}-\mathrm{L}$ & pXMJ19 carrying RiboJ and aro $E^{\mathrm{MU}}$ gene with low strength RBS & This study \\
\hline pXMJ19-GHBH & $\begin{array}{l}\text { Plasmid pXMJ19-RiboJ-aroG }{ }^{\mathrm{MU}}-\mathrm{H} \text { derivate, containing aroB-H module } \\
\text { (Ptac-RiboJ-aroB, aroB gene with high strength RBS) }\end{array}$ & This study \\
\hline pXMJ19-GHBHDH & $\begin{array}{l}\text { pXMJ19-GHBH derivate, containing aroD-H module (Ptac-RiboJ-aroD, aroD gene } \\
\text { with high strength RBS) }\end{array}$ & This study \\
\hline plasmid-1 & $\begin{array}{l}\text { pXMJ19-GHBHDH derivate, containing aroE-H module (Ptac-RiboJ-aroE, aroE gene } \\
\text { with high strength RBS) }\end{array}$ & This study \\
\hline plasmid-2 & $\begin{array}{l}\text { Plasmid pXMJ19-RiboJ-aroG } \mathrm{MU}_{-} \mathrm{H} \text { derivate, containing aroB-M module, aroD-M } \\
\text { module, aroE-M module }\end{array}$ & This study \\
\hline
\end{tabular}


Table 1 Bacterial strains and plasmids used in this study (Continued)

\begin{tabular}{|c|c|c|}
\hline plasmid-3 & Plasmid pXMJ19-RiboJ-aroG ${ }^{\mathrm{MU}}$-H derivate, containing aroB-L module, aroD-L module, aroE-L module & This study \\
\hline plasmid-4 & Plasmid pXMJ19-RiboJ-aroG ${ }^{\mathrm{MU}}-\mathrm{M}$ derivate, containing aroB-H module, aroD-M module, aroE-L module & This study \\
\hline plasmid-5 & Plasmid pXMJ19-RiboJ-aroG ${ }^{\mathrm{MU}}-\mathrm{M}$ derivate, containing aroB-M module, aroD-L module, aroE-H module & This study \\
\hline plasmid-6 & Plasmid pXMJ19-RiboJ-aro $\mathrm{G}^{\mathrm{MU}}-\mathrm{M}$ derivate, containing aroB-L module, aroD-H module, aroE-M module & This study \\
\hline plasmid-7 & Plasmid pXMJ19-RiboJ-aro $G^{\mathrm{MU}}$-L derivate, containing aroB-H module, aroD-L module, aroE-M module & This study \\
\hline plasmid-8 & Plasmid pXMJ19-RiboJ-aro $G^{\mathrm{MU}}-\mathrm{L}$ derivate, containing aroB-M module, aro $\mathrm{D}-\mathrm{H}$ module, aroE- $\mathrm{L}$ module & This study \\
\hline plasmid-9 & Plasmid pXMJ19-RiboJ-aro $G^{\mathrm{MU}}-\mathrm{L}$ derivate, containing aroB-L module, aroD-M module, aroE-H module & This study \\
\hline pXMJ19-GBTDE & Plasmid 2 derivate, containing a terminator between $\operatorname{aro} B$ and $\operatorname{aro} D$ Module & This study \\
\hline pXMJ19-GBTDTE & Plasmid pXMJ19-GBTDE derivate, containing a terminator between aroD and aroE module & This study \\
\hline pXMJ19-GTBTDTE & Plasmid pXMJ19-GBTDTE derivate, containing a terminator between aroG and aroB module & This study \\
\hline
\end{tabular}

\section{Discussion}

Several methods, such as overexpression of aro genes [31, 32] and the use of enzymes with improved properties [33], have been reported to enhance the metabolic flux into SA pathway, thus finally increase the production of aromatic amino acids or shikimic acid. This current study revealed a new synthetic biology strategy: Four aro genes were organized as continuous genetic modules and their transcriptions were coordinated by the same tac promoter, RiboJ and terminator. The translation levels of aro genes in the genetic modules were regulated by their RBS, which were quantatively characterized in this study.
RBS is vital to initiate genetic translation, and are useful synthetic biology parts for construction modules [16]. In this study, four tailored-made RBS libraries were constructed and the strength of each RBS sequence was determined in the background of C. glutamicum cells. Although the RBS libraries were tailored for aroG, aroB, aroD and $a r o E$, it is believed that these RBS would be applicable also for other purposes when C. glutamicum was used as host. Similarly, the constructed SA pathway modules were tested for SA production in this study, they should be also useful for productions such as aromatic amino acids that are derived from SA pathway.

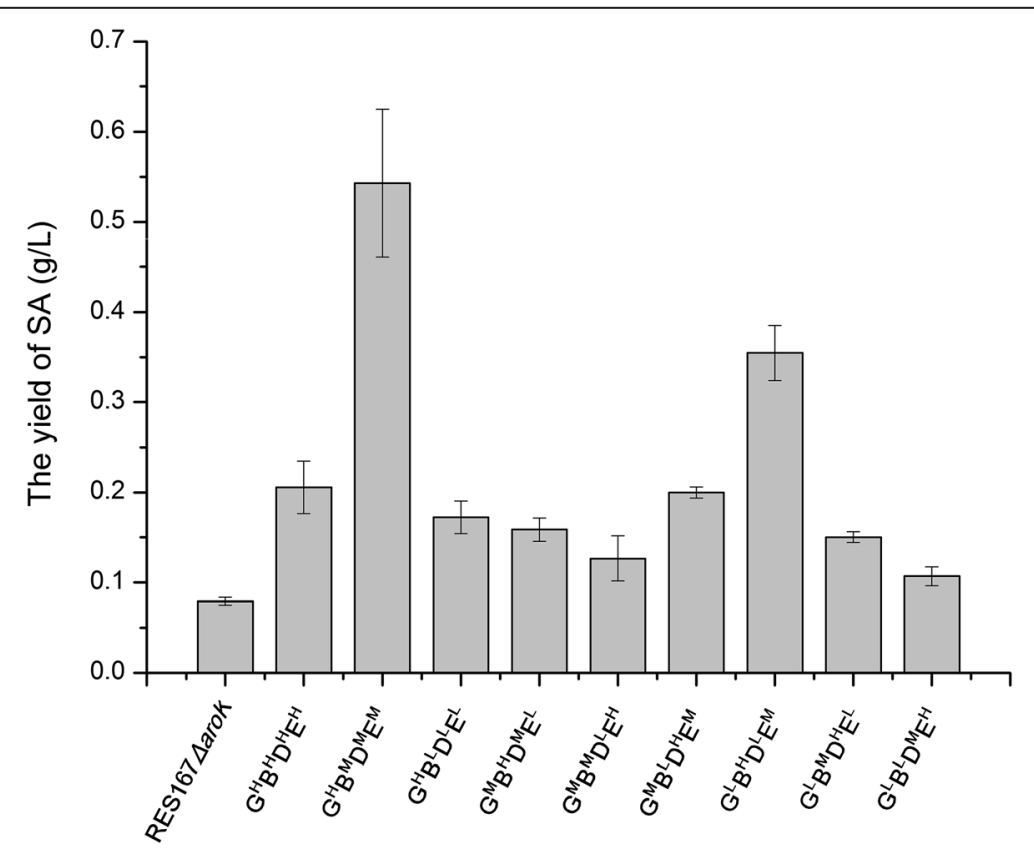

Fig. 5 Production of shikimic acid by C. glutamicum RES167 $\triangle$ aroK harboring various genetic modules. Three cultivations were conducted in 250-mL flasks and the standard deviations of shikimic acid production are indicated 


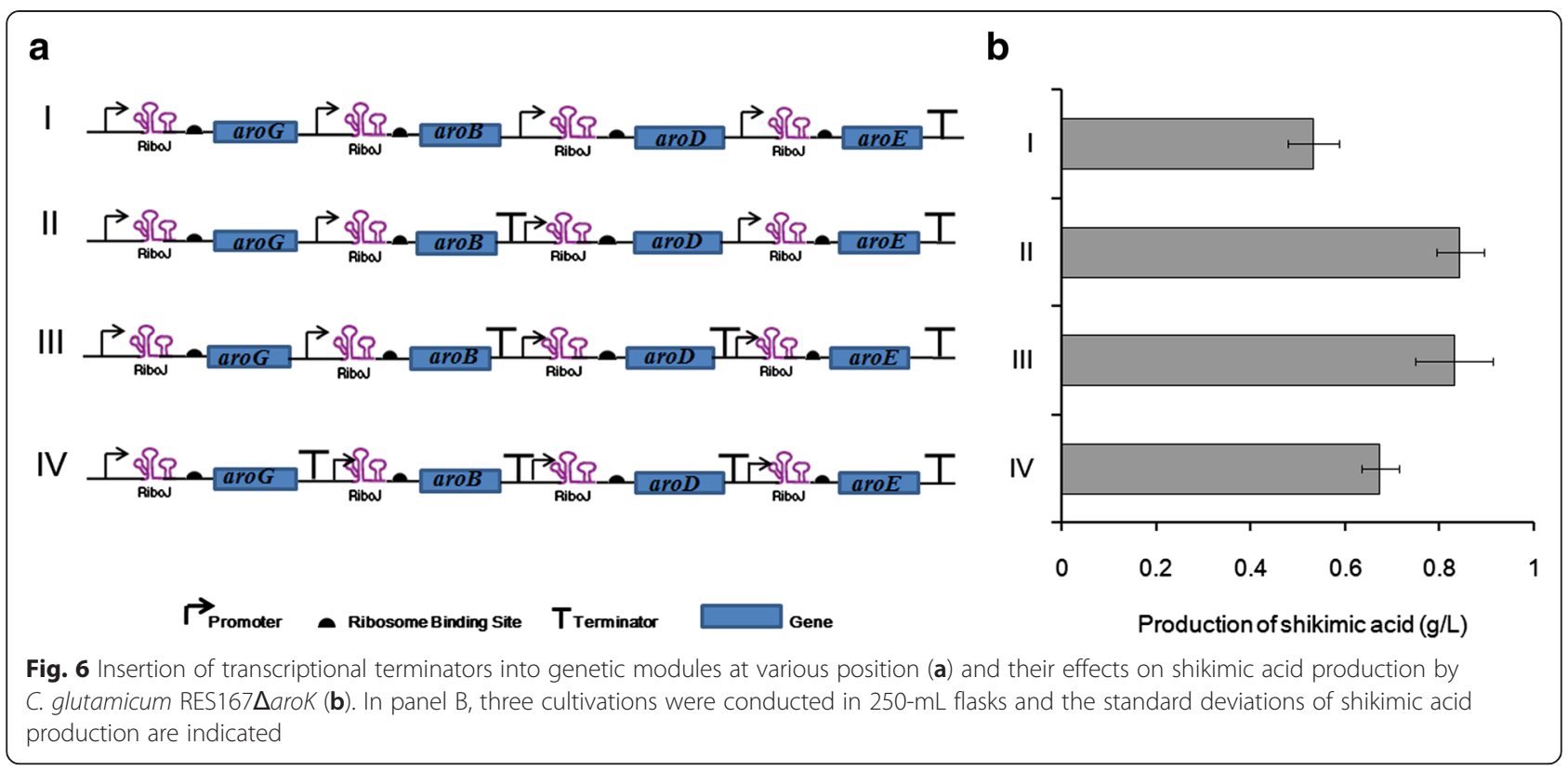

SA is a highly valued commercial compound. Efforts were made to improve SA production by de-repressing of feedback inhibition of enzymes involved in SA synthesis [33], increasing glucose availability [34], and optimizing metabolic fluxes [31], with E. coli or B. subtilis. So far as we know, C. glutamicum has not been exploited for SA production. By implementing the constructed genetic modules in the shikimate kinase deficient mutant, C. glutamicum was successfully engineered to produce SA at $11.3 \mathrm{~g} / \mathrm{L}$ in 5 -L fermenter. So far, this represents the highest titer of SA production with C. glutamicum. The SA production with C. glutamicum is comparable to the productivity with B. subtilis $(19.7 \mathrm{~g} / \mathrm{L})$ [35]. Although this SA titer is lower when compared to SA production by E. coli (84 g/L) [33], C. glutamicum is still a promising SA producer due to its non-pathogenic nature, and its productivity can be further improved by optimization of fermentation process, or by replacement of the tryptophan- and prephenate-sensitive DAHP synthase [36, 37].

\section{Conclusion}

Synthetic biology tool boxes for manipulating C. glutamicum were expanded by including 4 RBS libraries, in addition to the previous reported promoters $[38,39]$ and CoryneBrick [40]. The RBS libraries represent the first set of RBS libraries that were quantatively characterized in C. glutamicum. The selected RBS and aro genes could be organized as continuous genetic modules and their transcriptions could be coordinated. Genetic modules were successful constructed for SA pathway, and were demonstrated to be useful for increase of SA synthesis. In fed-batch fermentation, C. glutamicum harboring newly constructed SA pathway modules achieved $11.3 \mathrm{~g} / \mathrm{L}$ SA, which represented the highest SA production with C. glutamicum.

\section{Materials and methods}

\section{Microorganisms, plasmids, medium, and cultivation}

The bacterial strains and plasmids used in this study are listed in Table 1. C. glutamicum was cultivated at $30{ }^{\circ} \mathrm{C}$ in Luria Bertani (LB) [41] broth or Brain Heart Infusion (BHI) medium [42]. E. coli was cultivated at $37{ }^{\circ} \mathrm{C}$ in $50 \mathrm{~mL}$ of LB broth in 250-ml flasks on a rotary shaker at $200 \mathrm{rpm}$. When needed, chloramphenicol at a final concentration of 10 or $20 \mu \mathrm{g} / \mathrm{mL}$ in medium was used for cultivation of C. glutamicum or E. coli. Expression of genes with C. glutamicum was induced with $0.5 \mathrm{mM}$ isopropyl $\beta$-D-1-thiogalactopyranoside (IPTG).

Fermentative production of shikimic acid with C. glutamicum was carried out in $250 \mathrm{~mL}$ flasks and 5-L fermenter (Bioflo Model 3000 bioreactor, New Brunswick Scientific, N.J., U.S.A.). Seeding cultures were grown with Medium A (g/L): $\mathrm{K}_{2} \mathrm{HPO}_{4} \cdot 3 \mathrm{H}_{2} \mathrm{O}(0.5) ; \mathrm{KH}_{2} \mathrm{PO}_{4}$ (0.5); $\left(\mathrm{NH}_{4}\right)_{2} \mathrm{SO}_{4}$ (10); glucose (40); $\mathrm{MgSO}_{4} \cdot 7 \mathrm{H}_{2} \mathrm{O}(0.2)$; phenylalanine (0.15); tyrosine (0.15); tryptophan (0.15); $\mathrm{CaCO}_{3}$ (30); $\mathrm{FeSO}_{4} \cdot 7 \mathrm{H}_{2} \mathrm{O}(0.02) ; \mathrm{MnSO}_{4} \cdot 4 \mathrm{H}_{2} \mathrm{O}(0.02)$; biotin $(50 \mu \mathrm{g})$; thiamine $(200 \mu \mathrm{g})$, $\mathrm{pH}$ 7.4.

Fermentation was conducted with Medium B $(\mathrm{g} / \mathrm{L})$ : $\mathrm{K}_{2} \mathrm{HPO}_{4} \cdot 3 \mathrm{H}_{2} \mathrm{O}(0.5) ; \mathrm{KH}_{2} \mathrm{PO}_{4}$ (0.5); Urea (3); sucrose (38); $\mathrm{MgSO}_{4} \cdot 7 \mathrm{H}_{2} \mathrm{O}(0.2)$; Yeast extract (10); peptone (4); $\mathrm{FeSO}_{4} \cdot 7 \mathrm{H}_{2} \mathrm{O} \quad(0.02) ; \quad \mathrm{MnSO}_{4} \cdot 4 \mathrm{H}_{2} \mathrm{O} \quad(0.02) ;$ biotin $(50 \mu \mathrm{g})$; thiamine $(200 \mu \mathrm{g}), \mathrm{pH}$ 7.4. The fermenter was stirred at $300 \mathrm{rpm}$, aerated at $3.0 \mathrm{vol} / \mathrm{vol}$ per minute, and $\mathrm{pH}$ was maintained at 7.0. Cell growth was monitored by measuring optical density at $600 \mathrm{~nm}\left(\mathrm{OD}_{600}\right)$ 

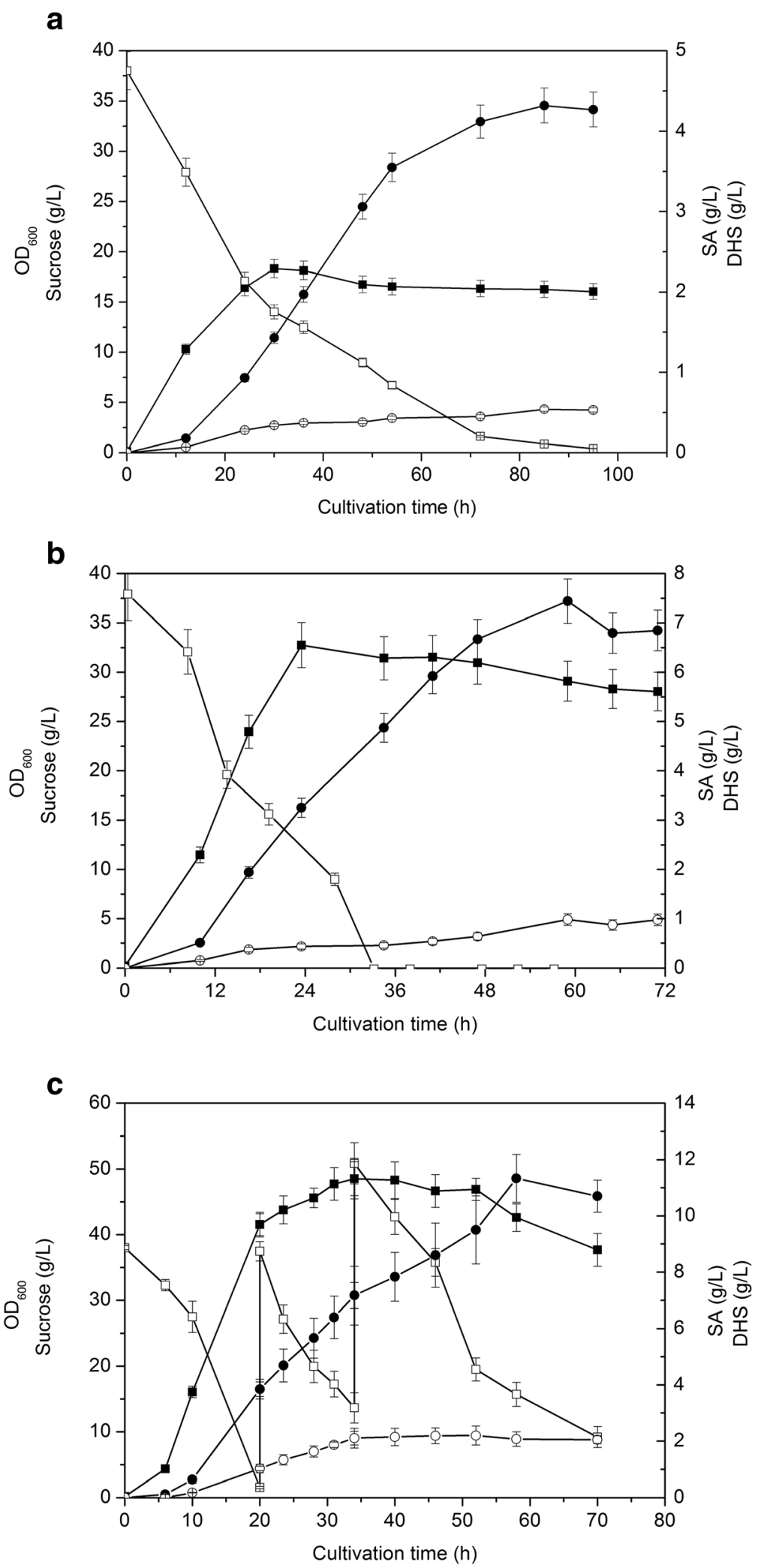

Fig. 7 The growth (solid squares), sucrose consumption (open squares), productions of shikimic acid (circles) and 3-dehydroshikimic acid (open circles) with recombinant C. glutamicum RES167 $\triangle$ aroK harboring pXMJ19-GBTDE, during shake-flask (a), batch (b), and fed-batch cultivation (c). Data are averages of three parallel fermentations 
with a spectrophotometer (Biospec-1601 DNA/Protein Enzyme Analyzer, Shimadzu). Cellular dry weights were determined by centrifugation and lyophilization with 3 parallel samples.

C. glutamicum was cultivated in mineral salts (MS) medium when RBS strength were tested. The MS medium contained following components ( $\mathrm{g} / \mathrm{L}, \mathrm{pH}$ 8.0): $\mathrm{Na}_{2} \mathrm{HPO}_{4} \cdot 12 \mathrm{H}_{2} \mathrm{O}$ (2); $\mathrm{KH}_{2} \mathrm{PO}_{4}(0.5) ; \quad \mathrm{MgSO}_{4} \cdot 7 \mathrm{H}_{2} \mathrm{O}$ (0.03); $\mathrm{NH}_{4} \mathrm{Cl}$ (0.53); trace element solution $2 \mathrm{~mL}$. Trace element solution (g/L, $\mathrm{pH}$ 6.0): EDTA, (0.5); $\mathrm{ZnSO}_{4}$. $7 \mathrm{H}_{2} \mathrm{O},(0.22) ; \mathrm{CaCl}_{2}, \quad(0.055) ; \mathrm{MnCl}_{2} \cdot 4 \mathrm{H}_{2} \mathrm{O},(0.051)$; $\mathrm{FeSO}_{4} \cdot 7 \mathrm{H}_{2} \mathrm{O}$, (0.0499); $\left(\mathrm{NH}_{4}\right)_{6} \mathrm{Mo}_{7} \mathrm{O}_{24} \cdot 4 \mathrm{H}_{2} \mathrm{O},(0.011)$; $\mathrm{CuSO}_{4} \cdot 5 \mathrm{H}_{2} \mathrm{O}$, (0.0157); $\mathrm{CoCl}_{2} \cdot 6 \mathrm{H}_{2} \mathrm{O}$, (0.0161); biotin (0.0125); thiamine (0.05).

\section{DNA extraction, amplification, plasmid construction and genetic transformation}

Plasmid and chromosomal DNAs were isolated using the OMEGA Plasmid Mini Kit and the OMEGA Bacterial DNA Kit (Omega genetics, Beijing), respectively. DNA fragments from PCR amplification were purified with the OMEGA Cycle-Pure Kit (Omega genetics, Beijing). Restriction enzymes, ligases and other DNAmanipulating enzymes were used according to their manufacturer's instructions. Genetic transformation of C. glutamicum and E. coli was carried out by electroporation, and recombinant strains were selected according to Tauch et al. [43].

\section{Construction of pXMJ19-aroG ${ }^{\mathrm{MU}}$, pXMJ19-aro $D^{\mathrm{MU}}$ pXMJ19-aro $B^{\mathrm{MU}}, \mathrm{pXMJ} 19-\operatorname{aro}^{\mathrm{MU}}$ and $\mathrm{pZB}$}

The aro genes, i.e., aroG (GenBank accession number, NP_601382.1), aroB (NP_600835.1), aroD (NP_599670.1), and aroE (NP_600843.1) were PCR amplified from genomic DNA of C. glutamicum RES167 using primers listed in Table 2. Subsequently, these aro genes were cloned into pXMJ19, generating pXMJ19-aroG, pXMJ19-aroB, pXMJ19-aroD, and pXMJ19-aroE. For subsequent cloning, the following silent mutations were made with primers listed in Table 1: the HindIII and PstI of aroG, BamHI and SpeI of $\operatorname{aroB}$, PstI of $a r o D$, and EcoRI and SalI of aroE. The resulting plasmids were named pXMJ19aro $G^{\mathrm{MU}}, \quad \mathrm{pXM} 19-\operatorname{aro} B^{\mathrm{MU}}, \quad \mathrm{pXM} 19-\operatorname{aro} D^{\mathrm{MU}}$, and pXMJ19-aroE $E^{\mathrm{MU}}$.

pZB was derived from pXMJ19. Chemically synthesized gene of RiboJ (27) was cloned into pXMJ19 at HindIII and PstI sites, resulting in pXMJ19-RiboJ. This pXMJ19-RiboJ was digested with EcoRI and KpnI, and a genetic fragment encoding the enhanced green fluorescence protein was cloned at the KpnI and EcoRI sites. The resulting plasmid was named $\mathrm{pZB}$, and was used for later construction of RBS libraries.
Design and construction of RBS libraries tailored for aroG, $\operatorname{aro} B$, aroD and $\operatorname{aroE}$, and evaluation of RBS strength according to fluorescence intensity

Based on the currently known RBS sequences from $C$. glutamicum, we designed a seeding sequence of AAAGG $(\mathrm{N})_{6-9}$, where " $\mathrm{N}$ " represents any nucleotide of A, T, G, or C. From this seeding sequence, oligonucleotides tagged as MU-RBSAG-F, MU-RBSAB-F, MURBSAD-F, and MU-RBSAE-F, were chemically synthesized. These oligonucleotides and their partner primers (Table 2) were used to amplify the aro genes from plasmid pXMJ19-aroG ${ }^{\mathrm{MU}}$, pXMJ19-aroB ${ }^{\mathrm{MU}}$, pXMJ19aro $D^{\mathrm{MU}}, \mathrm{pXMJ} 19-\operatorname{aroE}^{\mathrm{MU}}$. The amplified aro genes, each had a specific RBS sequence at its 5 '-end, were digested with restriction endonuclease and were cloned into the samely digested pZB. Thus, four RBS libraries were constructed and were named as pZB-aroG, pZBaroB, pZB-aroD, and pZB-aroE (Fig. 2).

The strength of each RBS for genetic translation was determined according to its fluorescence intensity. $C$. glutamicum cells harboring single plasmid (thus a single RBS) of libraries of pZB-aroG, pZB-aroB, pZB-aroD, and $\mathrm{pZB}-\operatorname{aroE}$ were cultivated in the presence of $0.5 \mathrm{mM}$ IPTG at $30{ }^{\circ} \mathrm{C}$ in MS medium. After incubation for $48 \mathrm{~h}$ at $30{ }^{\circ} \mathrm{C}$ and $200 \mathrm{rpm}, 200 \mu \mathrm{l}$ of cell suspension was transferred into a 96-well plate. The fluorescence from the eGFP in C. glutamicum cells and optical density were measured using a BioTek synergy $\mathrm{H} 4$ Hybrid Reader (Keruiente, Beijing, China).

\section{Construction of genetic modules for SA pathway}

To construct the nine plasmids with the combination of different strength RBS, aroG gene with high, middle and low strength RBS were amplified from pXMJ19$\operatorname{aro}^{\mathrm{MU}}$ and cloned between SalI and BamHI cloning sites of plasmid pXMJ19-RiboJ. These three plasmids were named as pXMJ19-RiboJ-aroG ${ }^{\mathrm{MU}}-\mathrm{H}$, pXMJ19RiboJ-aroG ${ }^{\mathrm{MU}}-\mathrm{M}$ and pXMJ19-RiboJ-aroG ${ }^{\mathrm{MU}}-\mathrm{L}$, respectively. Taking the same way, we got plasmids pXMJ19-RiboJ-aroB ${ }^{\mathrm{MU}}-\mathrm{H}$, pXMJ19-RiboJ-aroB ${ }^{\mathrm{MU}}-\mathrm{M}$, pXMJ19-RiboJ-aroB ${ }^{\mathrm{MU}}-\mathrm{L}, \quad$ pXMJ19-RiboJ-aroD ${ }^{\mathrm{MU}}-\mathrm{H}$, pXMJ19-RiboJ-aroD ${ }^{\mathrm{MU}}-\mathrm{M}$, pXMJ19-RiboJ-aroD ${ }^{\mathrm{MU}}-\mathrm{L}$, pXMJ19-RiboJ-aroE ${ }^{\mathrm{MU}}-\mathrm{H}, \quad$ pXMJ19-RiboJ-aroE $E_{-\mathrm{M}}^{\mathrm{MU}}$ and pXMJ19-RiboJ-aroE ${ }^{\mathrm{MU}}-\mathrm{L}$, which also have the high, middle and low strength RBS, accordingly. Then, Ptac-Ribol-aroB ${ }^{\mathrm{MU}}-\mathrm{H}$ fragments with BamHI and XmaI sites were amplified from plasmid pXMJ19-RiboJ-aro $B^{\mathrm{MU}}$ $\mathrm{H}$ and cloned into plasmid pXMJ19-RiboJ-aro $G^{\mathrm{MU}}-\mathrm{H}$, resulting plasmid named pXMJ19-GHBH. Then fragments Ptac-RiboJ-aroD ${ }^{\mathrm{MU}}-\mathrm{H}$ with $\mathrm{XmaI}$ and $\mathrm{KpnI}$ sites were cloned into plasmid pXMJ19-GHBH, resulting plasmid named pXMJ19-GHBHDH. From plasmid pXMJ19RiboJ-aroE ${ }^{\mathrm{MU}}-\mathrm{H}$ we got fragments Ptac-RiboJ-aroE ${ }^{\mathrm{MU}}$ $\mathrm{H}$ with KpnI and EcoRI sites and cloned the fragments 
Table 2 Oligonucleotides used in this study

\begin{tabular}{|c|c|c|}
\hline Primers & Sequences & Notes \\
\hline aroG-F & CGCGCGTCGACATGAATAGGGGTGTGAGTTG & \multirow{2}{*}{$\begin{array}{l}\text { Amplification of aroG from genome, } \\
\text { Sall and Kpnl underlined }\end{array}$} \\
\hline $\operatorname{aroG}-\mathrm{R}$ & CGCGCGGTACCTTAGTTACGCAGCATTTCTGCAACG & \\
\hline $\operatorname{aroB}-\mathrm{F}$ & CGCGCGTCGACATGAGCGCAGTGCAGATTTC & \multirow{2}{*}{$\begin{array}{l}\text { Amplification of aroB from genome, } \\
\text { Sall and Kpnl underlined }\end{array}$} \\
\hline $\operatorname{aroB}-\mathrm{R}$ & CGCGCGGTACCTTAGTGGCTGATTGCCTCATAGCA & \\
\hline aroD-F & CGCGCGTCGACATGCCTGGAA AAATTCTCCT & \multirow{2}{*}{$\begin{array}{l}\text { Amplification of aroD from genome, } \\
\text { Sall and Kpnl underlined }\end{array}$} \\
\hline $\operatorname{aroD}-\mathrm{R}$ & CGCGCGGTACCTTACTITITGAGATTTGCCAGGATA & \\
\hline $\operatorname{aroE}-\mathrm{F}$ & CGCGCCTGCATATGGGTTCTCACATCACTCAC & \multirow{2}{*}{$\begin{array}{l}\text { Amplification of aroE from genome, } \\
\text { Pstl and Kpnl underlined }\end{array}$} \\
\hline $\operatorname{aroE}-\mathrm{R}$ & CGCGCGGTACCTTAGTGTTCTTCTGAGATGCCT & \\
\hline MU-aroG-1-F & GGCCTTACCGTTGGCAACATCAGCCAGCTTCTGCTTCAGCTCAAGTACC & \multirow[t]{2}{*}{ Mutate Hindlll in aroG } \\
\hline MU-aroG-1-R & CCTGAGGTACTTGAGCTGAAGCAGAAGCTGGCTGATGTTG CCAACGGT & \\
\hline MU-aroG-2-F & TCGCGCCAACGTAAAGACTCTGCTCCAGATGGCAGTTGTTTGACCT & \multirow[t]{2}{*}{ Mutate Pstl in aroG } \\
\hline MU-aroG-2-R & CGTAGGTCAAAACAACTGCCATCTGGAGCAGAGTCTTTACGTTGGCGC & \\
\hline MU-aroG-3-F & GTGTCCGATGAGTCCCTGCGTGCTGCCGATATCTACTGCTCCCACGAGG & \multirow[t]{2}{*}{ Mutate Pstl in aroG } \\
\hline MU-aroG-3-R & AGCCTCGTGGGAGCAGTAGATATCGGCAGCACGCAGGGACTCATCGGAC & \\
\hline MU-aroB-1-F & GCCTGACGCGGAAATCATCGCGGGTTCCGCCGAAATCATCAAAACTGG & \multirow[t]{2}{*}{ Mutate BamHI in aroB } \\
\hline MU-aroB-1-R & AACCAGTTTGATGATTTCGGCGGAACCCGCGATGATTTCCGCGTCAGG & \\
\hline MU-aroB-2-F & CATCCGAGTTGGATGCAGCACTGGTCGCTGCTGGTTTGAAGGTCCTGC & \multirow[t]{2}{*}{ Mutate Spel in $\operatorname{aroB}$} \\
\hline MU-aroB-2-R & TGCAGGACCTTCAAACCAGCAGCGACCAGTGCTGCATCCAACTCGGATG & \\
\hline MU-aroD-F & TTAGCTCACCTTCGTGATTGCTCTGGAGCGCCTCAACCTCAAGGCCGTG & \multirow[t]{2}{*}{ Mutate Pstl in aroD } \\
\hline MU-aroD-R & GCACGGCCTTGAGGTTGAGGCGCTCCAGAGCAATCACGAAGGTGAGCT & \\
\hline MU-aroE-2-F & CATGCCGTCTAAATTCGCAGCTCTTGAATTTGCCGACGAAGTAACCGAACGCGCCTGC & \multirow[t]{2}{*}{ Mutate EcoRl in aroE } \\
\hline MU-aroE-2-R & GCAGGCGCGTTCGGTTACTTCGTCGGCAAATTCAAGAGCTGCGAATTTAGACGGCATG & \\
\hline MU-aroE-2-F & ATGGCGCGCCGACAACACCGACGTTGACGGCATCAGGGGAGCTCTCGG & \multirow[t]{2}{*}{ Mutate Sall in aroE } \\
\hline MU-aroE-2-R & CACCGAGAGCTCCCCTGATGCCGTCAACGTCGGTGTTGTCGGCGCGCC & \\
\hline RiboJ-F & CGCGAAGCTTAGCTGTCACCGGATGTGCTITCCGGTCTGATGAGTC & \multirow{2}{*}{$\begin{array}{l}\text { Amplification of RiboJ from pUC19, } \\
\text { Hindlll and Pstl underlined }\end{array}$} \\
\hline RiboJ-R & CGCGCTGCAGTTAAACAAAATTATTTGTAGAGGCTGTTTCG & \\
\hline EGFP-F & CGCGGGTACCGTGAGCAAGGGCGCCGAGC & \multirow{2}{*}{$\begin{array}{l}\text { Amplification of egfp from pACGFP, } \\
\text { Kpnl and EcoRI underlined }\end{array}$} \\
\hline EGFP-R & CGCGGAATTCTCACTTGTACAGCTCATCCATGCCGTGGGT & \\
\hline MU-RBSAG-F & CGCGCGTCGACAAAGGNNNNNNNNATGAATAGGGGTGTGAGTTG & \multirow{2}{*}{$\begin{array}{l}\text { Amplification of aroG with mutated RBS } \\
\text { Sall and Kpnl underlined }\end{array}$} \\
\hline MU-RBSAG-R & CGCGCGGTACCGTTACGCAGCATTTCTGCAACG & \\
\hline MU-RBSAB-F & CGCGCGTCGACAAAGGNNNNNNNNATGAGCGCAGTGCAGATTTC & \multirow{2}{*}{$\begin{array}{l}\text { Amplification of aroB with mutated RBS } \\
\text { Sall and Kpnl underlined }\end{array}$} \\
\hline MU-RBSAB-R & CGCGCGGTACCGTGGCTGATTGCCTCATAAGCA & \\
\hline MU-RBSAD-F & CGCGCGTCGACAAAGGNNNNNNNNATGCCTGGAAAAATTCTCCT & \multirow{2}{*}{$\begin{array}{l}\text { Amplification of aroD with mutated RBS } \\
\text { Sall and Kpnl underlined }\end{array}$} \\
\hline MU-RBSAD-R & CGCGCGGTACCCTITITGAGATTTGCCAGGATA & \\
\hline MU-RBSAE-F & CGCGCGTCGACAAAGGNNNNNNNNATGGGTTCTCACATCACTCAC & \multirow{2}{*}{$\begin{array}{l}\text { Amplification of aroE with mutated RBS, } \\
\text { Sall and Kpnl underlined }\end{array}$} \\
\hline MU-RBSAE-R & CGCGCGGTACCGTGTTCTTCTGAGATGCCT & \\
\hline aroG-H-F & CGCGCGTCGACAAAGGGTGAATCTATGAATAGGGGTGTGAGTTG & \multirow{2}{*}{$\begin{array}{l}\text { aroG with high strength RBS, } \\
\text { Sall and BamHI underlined }\end{array}$} \\
\hline aroG-H-R & CGCGCGGATCCTTAGTTACGCAGCATTTCTGCAACG & \\
\hline aroG-M-F & CGCGCGTCGACAAAGGTTCTAAAGATGAATAGGGGTGTGAGTTG & \multirow{2}{*}{$\begin{array}{l}\text { aroG with medium strength RBS, } \\
\text { Sall and BamHI underlined }\end{array}$} \\
\hline aroG-M-R & CGCGCGGATCCTTAGTTACGCAGCATTTCTGCAACG & \\
\hline $\operatorname{aroG-L-F}$ & CGCGCGTCGACAAAGGGCCGAATTATGAATAGGGGTGTGAGTTG & \multirow{2}{*}{$\begin{array}{l}\text { aroG with lows trength RBS, } \\
\text { Sall and BamHI underlined }\end{array}$} \\
\hline $\operatorname{aroG-L-R}$ & CGCGCGGATCCTTAGTTACGCAGCATTTCTGCAACG & \\
\hline $\operatorname{aroB}-\mathrm{H}-\mathrm{F}$ & CGCGCGTCGACAAAGGGGAGAGCCATGAGCGCAGTGCAGATTाTC & \multirow{2}{*}{$\begin{array}{l}\text { aroB with high strength RBS, } \\
\text { Sall and BamHI underlined }\end{array}$} \\
\hline $\operatorname{aroB}-\mathrm{H}-\mathrm{R}$ & CGCGCGGATCCTTAGTGGCTGATTGCCTCATAAGCA & \\
\hline
\end{tabular}


Table 2 Oligonucleotides used in this study (Continued)

\begin{tabular}{|c|c|c|}
\hline $\operatorname{aroB}-\mathrm{M}-\mathrm{F}$ & CGCGCGTCGACAAAGGCATGTTCTATGAGCGCAGTGCAGATTTC & \multirow{2}{*}{$\begin{array}{l}\text { aroB with medium strength RBS, } \\
\text { Sall and BamHI underlined }\end{array}$} \\
\hline $\operatorname{aroB}-\mathrm{M}-\mathrm{R}$ & CGCGCGGATCCTTAGTGGCTGATTGCCTCATAAGCA & \\
\hline $\operatorname{aroB}-\mathrm{L}-\mathrm{F}$ & CGCGCGTCGACAAAGGAACGACTAATGAGCGCAGTGCAGATITC & \multirow{2}{*}{$\begin{array}{l}\text { aroB with low strength RBS, } \\
\text { Sall and BamHlunderlined }\end{array}$} \\
\hline $\operatorname{aroB}-\mathrm{L}-\mathrm{R}$ & CGCGCGGATCCTTAGTGGCTGATTGCCTCATAAGCA & \\
\hline aroD-H-F & CGCGCGTCGACAAAGGAGGTTGTCATGCCTGGAAAAATTCTCCT & \multirow{2}{*}{$\begin{array}{l}\text { aroD with high strength RBS, } \\
\text { Sall and BamHI underlined }\end{array}$} \\
\hline $\operatorname{aroD}-\mathrm{H}-\mathrm{R}$ & CGCGCGGATCCTTACTITTTGAGATTTGCCAGGATA & \\
\hline aroD-M-F & CGCGCGTCGACAAAGGCATGGCCGATGCCTGGAAAAATTCTCCT & \multirow{2}{*}{$\begin{array}{l}\text { aroD with medium strength RBS, } \\
\text { Sall and BamHI underlined }\end{array}$} \\
\hline aroD-M-R & CGCGCGGATCCTTACTITTGAGATTTGCCAGGATA & \\
\hline $\operatorname{aroD}-\mathrm{L}-\mathrm{F}$ & CGCGCGTCGACAAAGGTGGTTCATATGCCTGGAAAAATTCTCCT & \multirow{2}{*}{$\begin{array}{l}\text { aroD with low strength RBS, } \\
\text { Sall and BamHI underlined }\end{array}$} \\
\hline $\operatorname{aroD}-\mathrm{L}-\mathrm{R}$ & CGCGCGGATCCTTACTTITTGAGATTTGCCAGGATA & \\
\hline $\operatorname{aroE}-\mathrm{H}-\mathrm{F}$ & CGCGCGTCGACAAAGGAGGATTAGATGGGTTCTCACATCACTCAC & \multirow{2}{*}{$\begin{array}{l}\text { aroE with high strength RBS, } \\
\text { Sall and BamHI underlined }\end{array}$} \\
\hline $\operatorname{aroE}-\mathrm{H}-\mathrm{R}$ & CGCGCGGATCCTTAGTGTTCTTCTGAGATGCCT & \\
\hline aroE-M-F & CGCGCGTCGACAAAGGAGAACGTGATGGGTTCTCACATCACTCAC & \multirow{2}{*}{$\begin{array}{l}\text { aroE with medium strength RBS, } \\
\text { Sall and BamHI underlined }\end{array}$} \\
\hline $\operatorname{aroE}-\mathrm{M}-\mathrm{R}$ & CGCGCGGATCCTTAGTGTTCTTCTGAGATGCCT & \\
\hline $\operatorname{aroE}-\mathrm{L}-\mathrm{F}$ & CGCGCGTCGACAAAGGGTTCATAGATGGGTTCTCACATCACTCAC & \multirow{2}{*}{$\begin{array}{l}\text { aroE with low strength RBS, } \\
\text { Sall and BamHI underlined }\end{array}$} \\
\hline $\operatorname{aroE-L-R}$ & CGCGCGGATCCTTAGTGTTCTTCTGAGATGCCT & \\
\hline PB-F & CGCGGGATCCTTGCGCCGACATCATAACGGTT & \multirow[t]{2}{*}{ BamHI and Xmal underlined } \\
\hline PB-R & CGCGCCCGGGTTAGTGGCTGATTGCCTCATAAGCA & \\
\hline PD-F & CGCGCCCGGGTTGCGCCGACATCATAACGGTT & \multirow[t]{2}{*}{ Xmal and Kpnl underlined } \\
\hline PD-R & CGCGGGTACCTTACTITITGAGATTTGCCAGGATA & \\
\hline PE-F & CGCGGGTACCTTGCGCCGACATCATAACGGTT & \multirow[t]{2}{*}{ Kpnl and EcoRI underlined } \\
\hline PE-R & CGCGGAATTCTTAGTGTTCTTCTGAGATGCCT & \\
\hline Terminator $1-\mathrm{F}$ & CGCGCCCGGGGGCTGTTITGGCGGATGAGAGAAGATTTC & \multirow[t]{2}{*}{ Xmal underlined } \\
\hline Terminator 1-R & CGCGCCCGGGAGAGTTGTAGAAACGCAAAAAGGCC & \\
\hline Terminator 2-F & CGCGGGTACCGGCTGTITGGCGGATGAGAGAAGATTTC & \multirow[t]{2}{*}{ Kpnl underlined } \\
\hline Terminator 2-R & CGCGGGTACCAGAGTTTGTAGAAACGCAAAAAGGCC & \\
\hline Terminator 3-F & CGCGGGATCCGGCTGTITGGCGGATGAGAGAAGATTTC & \multirow[t]{2}{*}{ BamHI underlined } \\
\hline Terminator 3-R & CGCGGGATCCAGAGTITGTAGAAACGCAAAAAGGCC & \\
\hline arok-F & CGCGGAATTCTGGCTGATTGCCTCATAAGCACTCT & \multirow[t]{2}{*}{ EcoRI and HindIII underlined } \\
\hline arok-R & CGCGAAGCTITTCGATGGACTACAGCAGGTGAATC & \\
\hline KTaroK-F & CGCGCCCGGGCCTCTAAACCTTCGAATTTCATTCGTTCCTC & \multirow[t]{2}{*}{ Xmal underlined } \\
\hline KTaroK-R & CGCGCCCGGGCGATTAATTAAACCGGGCACCTGATTAAC & \\
\hline V-KTaroK-F & TCCATGCTGGGCTGGTGCAAAATCGCTACC & \multirow[t]{2}{*}{ Primer used to verify $\Delta$ aroK } \\
\hline V-KTaroK-R & AACCATTGATATGGAAAACGGCAAGGCAGC & \\
\hline
\end{tabular}

into plasmid pXMJ19-GHBHDH, resulting plasmid named plasmid-1. Plasmid-2 to plasmid-9 and derivate plasmids were also got by the way describe above. Three terminator fragments with XmaI, BamHI and KpnI cloning sites were amplified from plasmid pXMJ19, respectively. After terminator with XmaI site was cloned in plasmid-2, we got plasmid pXMJ19GBTDE. Then terminator with BamHI site was cloned in plasmid pXMJ19-GBTDE to get plasmid pXMJ19GBTDTE. Plasmid pXMJ19-GTBTDTE was constructed by cloning terminator with KpnI site.

\section{Measurement of SA dehydrogenase activity}

The enzyme activities of the shikimate dehydrogenases were assayed by monitoring the absorbance of NADPH at $340 \mathrm{~nm}\left(\varepsilon=6230 \mathrm{M}^{-1} \mathrm{~cm}^{-1}\right)$ using a spectrophotometer (Specord 205 Analytik, Jena, Germany). The assays were conducted at $25{ }^{\circ} \mathrm{C}$ in a volume of $1 \mathrm{~mL}$ solution, containing $100 \mathrm{mM}$ Tris- $\mathrm{HCl}$ buffer at $\mathrm{pH}$ 8.0, $1 \mathrm{mM} \mathrm{SA}$, and $2 \mathrm{mM} \mathrm{NADP}^{+}$. Cellular lysates from C. glutamicum were added finally to trigger the reaction. One unit of enzyme activity was defined as the amount of enzyme catalyzing the conversion of $1 \mu \mathrm{mol}$ of $\mathrm{NADP}^{+}$per minute at $25^{\circ} \mathrm{C}$. 
For preparation of cellular lysates of C. glutamicum, cells were harvested by centrifugation $\left(6000 \mathrm{~g}, 4{ }^{\circ} \mathrm{C}\right.$, $5 \mathrm{~min}$ ) of culture samples. Supernatants were removed, the cell pellets were washed and re-suspended in $50 \mathrm{mM}$ $\mathrm{pH}$ 8.0 Tris- $\mathrm{HCl}$ buffer. This cell suspension was subjected to sonication (Ningbo Scientz Biotechnology Co., LTD, China) and centrifugation $\left(12,000 \mathrm{~g}, 4{ }^{\circ} \mathrm{C}, 10 \mathrm{~min}\right)$. The supernatants were collected and used for enzyme assays. Protein concentrations were determined using Bradford method [44].

\section{Construction of C. glutamicum RES167DaroK}

Disruption of the shikimate kinase gene, aroK, in C. glutamicum was performed using the suicide vector pK18mobsacB. The intact DNA fragment (2946 bp) of aroK was amplified from chromosomal DNA of C. glutamicum, using the primers aroK-F and aroK-R (Table 1). This intact aroK fragment was cloned into pK18mob$s a c B$ EcoRI/HindIII sites. The resulting plasmid was named pK18mobsacB-aroK, and was amplified with primers KTaroK-F and KTaroK-R, thus resulting DNA fragments with disrupted aroK gene. After digested with XmaI restriction endonuclease, DNA fragments were ligated and transformed into $E$. coli. The recombinant plasmid was named pK18mobsacB- $\triangle$ aroK and was electroporated into C. glutamicum RES167. Using the method described by Schäfer et al. [45], the aroK mutant RES167 4 aroK was screened out on BHI agar plates. The Disruption of aroK was verified by PCR amplification and sequence of the disrupted aroK gene from RES167 $\triangle$ aroK.

\section{Determination of SA and 3-dehydroshikimic acid concentrations}

The concentrations of SA and 3-dehydroskimic acid were determined with an HPLC system (Agilent 1200 series, Agilent Technologies, Inc., USA) equipped with a ZORBAX SB C18 column (4.6 mm x $250 \mathrm{~mm}$ x $5 \mu \mathrm{m}$ ) and detected at $215 \mathrm{~nm}$ wavelength. The HPLC was run with a mixture of solution A (phosphoric acid in water, pH 2.5) and solution B (methanol) as eluant and was operated at a flow rate of $0.35 \mathrm{~mL} / \mathrm{min}$. The following gradient was used: at $0-7.5 \mathrm{~min}, 95 \%$ of solution $\mathrm{A}$ and $5 \%$ of solution B; at 7.5-15 min, $100 \%$ of solution B; 15.0 $22.5 \mathrm{~min}, 95 \%$ of solution A and $5 \%$ of solution B. Standard shikimic acid (Cat. No. S5375, Sigma-Aldrich, USA) and 3-dehydroshikimic acid (Cat. No. 05616, Sigma-Aldrich, USA) were eluted at 5.411 and $6.241 \mathrm{~min}$, respectively, under these conditions.

\section{Determination of sucrose concentrations}

The sucrose concentrations in fermentation broth were determined with spectrometric method, as previously described [46].

\section{Competing interests}

The authors declare that they have no competing interests.

\section{Authors' contributions}

BZ and NZ carried out the experimental work, BZ drafted the manuscript. YML and $C L$ and $C B L$ participated in experimental design. CYJ and SJL supervised the research and finalized the manuscript. All authors read and approved the final manuscript.

\section{Acknowledgements}

This work was supported by 973 Project from Ministry of Science and Technology (No. 2012CB7211-04).

\section{Author details}

${ }^{1}$ State Key Laboratory of Microbial Resources, Institute of Microbiology, Chinese Academy of Sciences, Beichen-Xilu No.1, 100101 Beijing, PR China. ${ }^{2}$ CAS Key Laboratory of Microbial Physiology and Metabolic Engineering, Institute of Microbiology, Chinese Academy of Sciences, 100101 Beijing, PR China. ${ }^{3}$ University of Chinese Academy of Sciences, 100101 Beijing, PR China.

Received: 3 March 2015 Accepted: 6 May 2015

Published online: 17 May 2015

\section{References}

1. Herrmann KM. The shikimate pathway: early steps in the biosynthesis of aromatic compounds. Plant Cell. 1995;7:907-19.

2. Krämer M, Bongaerts J, Bovenberg R, Kremer S, Müller U, Orf S, et al. Metabolic engineering for microbial production of shikimic acid. Metab Eng. 2003;5:277-83.

3. Tzin V, Galili G. New insights into the shikimate and aromatic amino acids biosynthesis pathways in plants. Mol Plant. 2010;3:956-72.

4. Quiroz DCD, Carmona SB, Bolívar F, Escalante A. Current perspectives on applications of shikimic and aminoshikimic acids in pharmaceutical chemistry. Res Rep Med Chem. 2014;4:35-46.

5. Weber C, Bruckner C, Weinreb S, Lehr C, Essl C, Boles E. Biosynthesis of cis, cis-Muconic acid and its aromatic precursors, catechol and protocatechuic acid, from renewable feedstocks by Saccharomyces cerevisiae. Appl Environ Microbiol. 2012;78:8421-30.

6. Liao HF, Lin LL, Chien HR, Hsu WH. Serine 187 is a crucial residue for allosteric of Corynebacterium glutamicum 3-deoxy-D-arabino-heptulosonate7-phosphate synthase. FEMS Microbiol Lett. 2001;194:59-64.

7. Han MA, Lee HS, Cheon Cl, Min KH MSL. Cloning and analysis of the aroB gene encoding dehydroquinate synthase from Corynebacterium glutamicum. Can J Microbiol. 1999;45:885-90.

8. Liu C, Liu YM, Sun QL, Jiang C, Liu SJ. Unraveling the kinetic diversity of microbial 3-dehydroquinate dehydratases of shikimate pathway. AMB Express. 2015;5:1-7.

9. Kubota T, Tanaka Y, Hiraga K, Inui M, Yukawa H. Characterization of shikimate dehydrogenase homologues of Corynebacterium glutamicum. Appl Microbiol Biotechnol. 2013;97:8139-49.

10. Ajikumar PK, Xiao WH, Tyo KE, Wang Y, Simeon F, Leonard E, et al. Isoprenoid pathway optimization for Taxol precursor overproduction in Escherichia coli. Science. 2010;330:70-4.

11. Brophy JA, Voigt CA. Principles of genetic circuit design. Nat Methods. 2014;11:508-20.

12. Schendzielorz G, Dippong M, Grunberger A, Kohlheyer D, Yoshida A, Binder $S$, et al. Taking control over control: Use of product sensing in single cells to remove flux control at Key enzymes in biosynthesis pathways. ACS Synth Biol. 2014;3:21-9.

13. Oyarzun DA, Stan GB. Synthetic gene circuits for metabolic control: design trade-offs and constraints. J R Soc Interface. 2012;10:13-26.

14. Mutalik VK, Guimaraes JC, Cambray G, Lam C, Christoffersen MJ, Mai QA, et al. Precise and reliable gene expression via standard transcription and translation initiation elements. Nat Methods. 2013;10:354-60.

15. Chen YJ, Liu P, Nielsen AA, Brophy JA, Clancy K, Peterson T, et al. Characterization of 582 natural and synthetic terminators and quantification of their design constraints. Nat Methods. 2013;10:659-64.

16. Nowroozi FF, Baidoo EE, Ermakov S, Redding-Johanson AM, Batth TS, Petzold CJ, et al. Metabolic pathway optimization using ribosome binding site variants and combinatorial gene assembly. Appl Microbiol Biotechnol. 2014;98:1567-81. 
17. Binder S, Siedler S, Marienhagen J, Bott M, Eggeling L. Recombineering in Corynebacterium glutamicum combined with optical nanosensors: a general strategy for fast producer strain generation. Nucleic Acids Res. 2013;41:6360-9.

18. Krause FS, Blombach B, Eikmanns BJ. Metabolic engineering of Corynebacterium glutamicum for 2-ketoisovalerate production. Appl Environ Microbiol. 2010;76:8053-61.

19. Stabler N, Oikawa T, Bott M, Eggeling L. Corynebacterium glutamicum as a host for synthesis and export of D-Amino Acids. J Bacteriol. 2011;193:1702-9.

20. Rittmann D, Lindner SN, Wendisch VF. Engineering of a glycerol utilization pathway for amino acid production by Corynebacterium glutamicum. Appl Environ Microbiol. 2008;74:6216-22.

21. Ravasi P, Peiru S, Gramajo H, Menzella HG. Design and testing of a synthetic biology framework for genetic engineering of Corynebacterium glutamicum. Microb Cell Fact. 2012;11:147.

22. Litsanov B, Kabus A, Brocker M, Bott M. Efficient aerobic succinate production from glucose in minimal medium with Corynebacterium glutamicum. Microb Biotechnol. 2012;5:116-28.

23. Wieschalka S, Blombach B, Bott M, Eikmanns BJ. Bio-based production of organic acids with Corynebacterium glutamicum. Microb Biotechnol. 2013:6:87-102

24. Wieschalka S, Blombach B, Eikmanns BJ. Engineering Corynebacterium glutamicum for the production of pyruvate. Appl Microbiol Biotechnol. 2012;94:449-59.

25. Amador E, Castro JM, Correia A, Martin JF. Structure and organization of the $r r n D$ operon of 'Brevibacterium lactofermentum': analysis of the $16 \mathrm{~s} r \mathrm{RNA}$ gene. Microbiology. 1999;145:915-24.

26. Martín JF, Barreiro C, González-Lavado E, Barriuso M. Ribosomal RNA and ribosomal proteins in corynebacteria. J Biotechno. 2003;104:41-53.

27. Pfeifer-Sancar K, Mentz A, Rückert C, Kalinowski J. Comprehensive analysis of the Corynebacterium glutamicum transcriptome using an improved RNAseq technique. BMC Genomics. 2013:14.

28. Liu Q, Ouyang SP, Kim J, Chen GQ. The impact of PHB accumulation on L-glutamate production by recombinant Corynebacterium glutamicum. J Biotechnol. 2007;132:273-9.

29. Cinelli RAG, Ferrari A, Beltram F, Pellegrini V, Tyagi M, Giacca M. The enhanced green fluorescent protein as a tool for the analysis of protein dynamics and localization: local fluorescence study at the single-molecule level. Photochem Photobiol. 2000;71:771-6.

30. Lou C, Stanton B, Chen YJ, Munsky B, Voigt CA. Ribozyme-based insulator parts buffer synthetic circuits from genetic context. Nat Biotechnol. 2012;30:1137-42

31. Liu DF, Ai GM, Zheng QX, Liu C, Jiang CY, Liu LX, et al. Metabolic flux responses to genetic modification for shikimic acid production by Bacillus subtilis strains. Microb Cell Fact. 2014;13:40.

32. Cui YY, Ling C, Zhang YY, Huang J, Liu JZ. Production of shikimic acid from Escherichia coli through chemically inducible chromosomal evolution and cofactor metabolic engineering. Microb Cell Fact. 2014;13:21.

33. Chandran SS, Yi J, Draths KM, von Daeniken R, Webe W, Frost JW. Phosphoenolpyruvate availability and the biosynthesis of shikimic acid. Biotechnol Prog. 2003;19:808-14.

34. Escalante A, Calderon R, Valdivia A, de Anda R, Hernandez G, Ramirez OT, et al. Metabolic engineering for the production of shikimic acid in an evolved Escherichia coli strain lacking the phosphoenolpyruvate: carbohydrate phosphotransferase system. Microb Cell Fact. 2010;9:21.

35. Iomantas YAV, Abalakina EG, Polanue BM, Yampolskaya TA, Bachina TA, Kozlov YI. Method for producing shikimic acid. U.S. 2002.

36. Liu YJ, Li PP, Zhao KX, Wang BJ, Jiang CY, Drake HL, et al. Corynebacterium glutamicum contains 3-deoxy-D-arabino-heptulosonate 7-phosphate synthases that display novel biochemical features. Appl Environ Microbiol. 2008;74:5497-503.

37. Li PP, Li DF, Liu D, Liu YM, Liu C, Liu SJ. Interaction between DAHP synthase and chorismate mutase endows new regulation on DAHP synthase activity in Corynebacterium glutamicum. Appl Microbiol Biotechnol. 2013;97:10373-80.

38. Pauling J, Rottger R, Tauch A, Azevedo V, Baumbach J. CoryneRegNet 6.0-Updated database content, new analysis methods and novel features focusing on community demands. Nucleic Acids Res. 2012;40:D610-4.

39. Patek M, Holatko J, Busche T, Kalinowski J, Nesvera J. Corynebacterium glutamicum promoters: a practical approach. Microb Biotechnol. 2013;6:103-17.
40. Kang MK, Lee J, Um Y, Lee TS, Bott M, Park SJ. Synthetic biology platform of CoryneBrick vectors for gene expression in Corynebacterium glutamicum and its application to xylose utilization. Appl Microbiol Biotechnol. 2014:98:5991-6002.

41. Sezonov G, Joseleau-Petit D, D'Ari R. Escherichia coli physiology in Luria-Bertani broth. J Bacteriol. 2007;189:8746-9.

42. Georgi T, Rittmann D, Wendisch VF. Lysine and glutamate production by Corynebacterium glutamicum on glucose, fructose and sucrose: roles of malic enzyme and fructose-1,6-bisphosphatase. Metab Eng. 2005;7:291-301.

43. Tauch A, Kirchner O, Loffler B, Gotker S, Puhler A, Kalinowski J. Efficient electrotransformation of Corynebacterium diphtheriae with a mini-replicon derived from the Corynebacterium glutamicum plasmid pGA1. Curr Microbiol. 2002:45:362-7.

44. Bradford MM. A rapid and sensitive method for the quantitation of microgram quantities of protein utilizing the principle of protein-dye binding. Anal Chem. 1976;72:248-54.

45. Schäfer A, Tauch A, Jäger W, Kalinowski J, Thierbachb G, Pühler G. Small mobilizable multi-purpose cloning vectors derived from the Escherichia coli plasmids pK18 and pK19: selection of defined deletions in the chromosome of Corynebacterium glutamicum. Gene. 1994;145:69-73.

46. Wu H, Li Q, Lu R, Wang Y, Zhuang X, He N. Fed-batch production of a bioflocculant from Corynebacterium glutamicum. J Ind Microbiol Biotechnol. 2010;37:1203-9.

\section{Submit your next manuscript to BioMed Central and take full advantage of:}

- Convenient online submission

- Thorough peer review

- No space constraints or color figure charges

- Immediate publication on acceptance

- Inclusion in PubMed, CAS, Scopus and Google Scholar

- Research which is freely available for redistribution 